\title{
Hubungan Pengetahuan dan Tindakan Ibu dengan Peningkatan Status Gizi Balita yang Mengalami Gizi Kurang di Puskesmas Bromo Medan Tahun 2018
}

\section{Relationship between Mother's Knowledge and Actions with Improving Nutritional Status of Toddlers Experiencing Malnutrition in Bromo Medan Health Center in 2018}

\author{
Yusridawati(1) \& Yuvi Kawati(2) \\ Program Studi Ilmu Keperawatan, Sekolah Tinggi Ilmu Kesehatan RS Haji Medan, Indonesia \\ Diterima : 30 April 2020; Disetujui : 30 April 2020; Dipublish : 30 April 2020 \\ *Corresponding author: E-mail: yusridawati5@gmail.com
}

\begin{abstract}
Abstrak
Status gizi balita memiliki pengaruh yang sangat besar dalam mewujudkan sumber daya manusia yang berkualitas dimasa yang akan datang. Status gizi berhubungan dengan kecerdasan anak.Semakin rendah asupan zat gizi yang diterima, semakin rendah pula status gizi dan tingkat kecerdasan anak.Penelitian ini bertujuan untuk mengetahui hubungan pengetahuan dan tindakan ibu tentang peningkatan status gizi balita yang mengalami gizi kurang di Puskesmas Bromo Medan Tahun 2018. Penelitian ini menggunakan desain observasional analitik dengan pendekatan cross sectional. Sampelnya adalah Ibu yang mempunyai balita gizi kurang di wilayah kerja Puskesmas Bromo Medan, sebanyak 23 orang, dengan teknik total sampling. Pengumpulan data menggunakan kuesioner yang diolah melalui proses editing, coding, data entry, tabulating/processing. Analisa data dilakukan dengan uji Chi Square. Dari 23 responden, yang mempunyai pengetahuan cukup 12 responden (52,2\%) dengan pengetahuan kurang 7 responden (30,4\%), dan tindakan ibu dengan baik 6 responden $(26,1 \%)$ dengan tindakan buruk 17 responden $(73,9 \%)$. Serta peningkatan status gizi baik 10 responden (43,5\%) dan dengan peningkatan status gizi buruk 13 responden (56,5\%). Hasil penelitian diperoleh analisis p value sebesar 0,002, nilai batas kemaknaan $<0,05$, maka $\mathrm{H}_{\mathrm{a}}$ diterima dan $\mathrm{H}_{\mathrm{o}}$ ditolak. Kesimpulan penelitian ini adalah ada hubungan pengetahuan dan tindakan ibu tentang peningkatan status gizi balita yang mengalami gizi kurang di Puskesmas Bromo Medan tahun 2018.Disarankan kepada peneliti selanjutnya agar dapat memperluas dan mengembangkan judul ini menjadi lebih baik.
\end{abstract}

Kata Kunci : Pengetahuan Ibu; Tindakan Ibu; Peningkatan Status Gizi Balita.

\begin{abstract}
Nutritional status of toddlers has a huge influence in realizing quality human resources in the future. Nutritional status related to children's intelligence. The lower the nutrient intake received, the lower the nutritional status and level of intelligence of children. This study aims to determine the relationship of knowledge and actions of mothers about improving the nutritional status of children who experience malnutrition in the Bromo Medan Health Center in 2018. This study used an observational analytic design with a cross sectional approach. The sample is a mother who has a malnourished toddler in the working area of Bromo Medan Health Center, as many as 23 people, with a total sampling technique. Data collection uses a questionnaire that is processed through the process of editing, coding, data entry, tabulating / processing. Data analysis was done by Chi Square test. Of the 23 respondents, had enough knowledge 12 respondents (52.2\%) with less knowledge 7 respondents (30.4\%) and good mother's actions 6 respondents (26.1\%) with bad actions 17 respondents (73, 9\%). And an increase in good nutritional status of 10 respondents (43.5\%) and with an increase in malnutrition status of 13 respondents (56.5\%). The results of the study obtained an analysis of $p$ value of 0.002, the significance limit value $<0.05$, then Ha was accepted and Ho was rejected. The conclusion of this study is that there is a relationship between knowledge and actions of mothers about improving the nutritional status of children who experience malnutrition in the Bromo Medan Health Center in 2019. It is recommended to further researchers to be able to expand and develop this title for the better.
\end{abstract}

Keywords: Mother's Knowledge; Mother's Actions ; Improvement Of Nutritional Status Of Children 


\section{PENDAHULUAN}

Status gizi balita memiliki pengaruh yang sangat besar dalam mewujudkan sumber daya manusia yang berkualitas di masa yang akan datang. Status gizi berhubungan dengan kecerdasan anak. Pembentukan kecerdasan saat usia dini tergantung pada asupan zat gizi yang diterima oleh anak. Semakin rendah asupan zat gizi yang diterima, semakin rendah pula status gizi dan tingkat kecerdasan anak. Gizi kurang atau buruk pada masa bayi dan anakanak terutama usia kurang dari 5 tahun dapat berakibat terganggunya pertumbuhan jasmani dan kecerdasan anak (Rahmatillah, 2018)

Data detil untuk Provinsi Sumatera Utara pada tahun 2013, ditemukan fakta bahwa prevalensi balita gizi buruk dan kurang sebesar 22,4\% yang terdiri dari $8,3 \%$ gizi buruk dan $14,1 \%$ gizi kurang. Angka ini lebih tinggi 2,8\% denganangka prevalensi gizi berat kurang nasional yaitu 19,6\%. Jika dibandingkan angka provinsi tahun $2007(22,7 \%)$ dan tahun 2010 (21,3\%) tidak ada penurunan yang signifikan. Meskipun ada penurunan sebesar 0,6\% dari tahun 2007 ke tahun 2010 namun terjadi kenaikan kembali sebesar 0,5\% (gizi buruk) dan $0,6 \%$ untuk gizikurang pada tahun 2013. Dengan angka sebesar $22,4 \%$ prevalensi gizi kurang dan gizi buruk di Sumatera Utara masih termasuk dalam kategori tinggi (standar WHO; 5-9\% rendah, $10-19 \%$ medium, $20-39 \%$ tinggi, $>40 \%$ sangat tinggi) . (Kemenkes RI, 2013).

Salah satu upaya perbaikan gizi masyarakat adalah pemantauan status gizi balita.Dengan melihat perkembangan status gizi balita, dapat diketahui perkembangan dan pertumbuhan anak, sehingga dapat diketahui bila ada kelainan pada balita.Kegiatan pemantauan perkembangan status gizi balita dilaksanakan melalui penimbangan setiap bulan pada balita di posyandu.Berdasarkan penimbangan tersebut didapatkan data jumlah balita ditimbang, balita dengan berat badan naik (dibandingkan dengan berat badan bulan sebelumnya), dan balita yang dikategorikan BGM (Berat Badan Dibawah Garis Merah). Pada tahun 2015 dilaporkan bahwa dari jumlah balita yang ditimbang sebanyak 202.841 orang (laki-laki 72.443; Perempuan 130.398) terdapat $0.7 \%$ (1.440 orang) balita yang BGM (Laki-laki 517; Perempuan 921) di Kota Medan. Sedangkan ditahun 2016, dilaporkan jumlah balita yang ditimbang sebanyak 176.882 orang (laki-laki 73.218 dan perempuan 103.664) terdapat $0.81 \%$ (1.437 orang) balita yang mengalami BGM (Laki-laki 631; Perempuan 806) di Kota Medan. Jika dilihat jumlah ini mengalami 
peningkatan bila dibandingkan dengan tahun sebelumnya (Dinkes Medan, 2016).

Hasil survei pendahuluan yang dilakukan di wilayah kerja Puskesmas Bromo tahun 2018 ditemukan balita gizi kurang sejumlah 23 orang $(1.1 \%)$ dari 2093 balita. Berdasarkan hasil wawancara terhadap 23 orang ibu terdapat 15 orang ibu mengerti tentang gizi seimbang, sedangkan 8 orang ibu tidak mengerti tentang gizi seimbang. Selain itu masih ada ibu yang tidak membawa anaknya ke posyandu setiap bulannya, dan masih ada ibu yang memberikan sarapan di atas jam 9 dengan alasan disibukkan dengan pekerjaannya yang mana sebagian besar ibu bekerja mencari nasi busuk untuk ternak, dan beberapa diantaranya ibu hanya memberikan makanan pokok saja serta sangat jarang memberikan buah dan sayur kepada anaknya. Berdasarkan hasil wawancara juga didapat bahwa ibu memberikan makan anaknya dalam porsi yang sedikit, karena ibu takut makanan akan bersisa, para ibu juga tidak mengenal PGS (Pedoman Gizi Seimbang) sebagai pedoman dan lebih mengetahui 4 sehat 5 sempurna.

Penelitian ini bertujuan untuk mengidentifikasi Hubungan Pengetahuan dan Tindakan Ibu Dengan Peningkatan Status Gizi BalitaYang Mengalami Gizi Kurang di wilayah kerja Puskesmas Bromo Medan Tahun 2018 “.

\section{METODE PENELITIAN}

Jenis penelitian ini adalah penelitian observasional analitik yaitu penelitian yang dilakukan tanpa melakukan intervensi terhadap subyek penelitian (masyarakat) yang diarahkan untuk menjelaskan suatu keadaan atau situasi (Notoatmodjo, 2010).

Desain penelitian ini menggunakan pendekatan cross sectional dengan menekankan waktu pengukuran dan observasi data antara variabel dependen dan independen serta dilakukan satu kali pada satu saat (point time approach) (Nursalam, 2011).

Lokasi penelitian ini dilakukan di Puskesmas Bromo Tahun 2018. Alasan peneliti memilih tempat tersebut karena masalah gizi kurang berdasarkan $\mathrm{BB} / \mathrm{U}$ yang terdapat diwilayah kerja Puskesmas Bromo sebanyak 23 orang gizi kurang dan 2 oranggizi buruk, serta belum ada penelitian sejenis dengan judul hubungan pengetahuan dan tindakan ibu dengan peningkatan status gizi balita yang mengalami gizi kurang di Puskesmas Bromo Tahun 2018.

Sampel pada penelitian ini adalah semua jumlah populasi dijadikan sampel.Jumlah sampel pada penelitian ini adalah 23 orang, dengan waktu penelitian \pm 1 bulan. 
Tabel 1 Defenisi Operasional

\begin{tabular}{|c|c|c|c|c|}
\hline Variabel & $\begin{array}{l}\text { Defenisi } \\
\text { Operasional }\end{array}$ & Alat Ukur & Hasil ukur & $\begin{array}{l}\text { Skala } \\
\text { Ukur }\end{array}$ \\
\hline \multicolumn{5}{|l|}{ Independen } \\
\hline Pengetahuan & $\begin{array}{l}\text { Kemampuan ibu } \\
\text { memahami } \\
\text { segala informasi } \\
\text { yang } \\
\text { berhubungan } \\
\text { dengan bahan } \\
\text { makanan yang } \\
\text { mengandung zat } \\
\text { gizi dan } \\
\text { pemenuhan } \\
\text { kecukupan gizi } \\
\text { bagi balita, sesuai } \\
\text { dengan pedoman } \\
\text { umum gizi } \\
\text { seimbang. }\end{array}$ & $\begin{array}{l}\text { Kuesioner } \\
\text { terdiri dari } 10 \\
\text { pertanyaan } \\
\text { Benar nilai : } 1 \\
\text { Salah nilai : } 0\end{array}$ & $\begin{array}{l}\text { 1. Baik : Benar } \\
\text { (7 - } 10 \text { soal) } \\
\text { 2. Cukup : Benar } \\
\text { (4 - } 6 \text { soal) } \\
\text { 3. Kurang : Benar } \\
\text { (0-3 soal) }\end{array}$ & Ordinal \\
\hline Tindakan & $\begin{array}{lr}\text { Tindakan/ } \\
\text { respon ibu } \\
\text { terhadap upaya } \\
\text { pemenuhan gizi } \\
\text { balita yang } \\
\text { mengalami gizi } \\
\text { kurang }\end{array}$ & $\begin{array}{l}\text { Kuesioner } \\
\text { terdiri dari } 10 \\
\text { pertanyaan } \\
\text { Setuju nilai : } 1 \\
\text { Tidak setuju } \\
\text { nilai : } 0\end{array}$ & 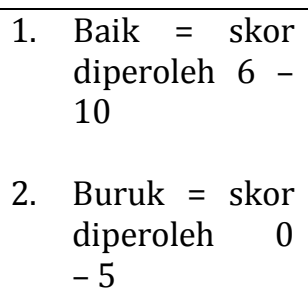 & Ordinal \\
\hline \multicolumn{5}{|l|}{ Dependen } \\
\hline $\begin{array}{l}\text { Peningkatan } \\
\text { status gizi }\end{array}$ & $\begin{array}{l}\text { Hasil interaksi } \\
\text { masukan } \\
\text { berbagai zat gizi } \\
\text { ke dalam tubuh } \\
\text { balita }\end{array}$ & $\begin{array}{l}\text { Kuesioner } \\
\text { terdiri dari } 10 \\
\text { pertanyaan } \\
\text { Setuju nilai : } 1 \\
\text { Tidak setuju } \\
\text { nilai : } 0\end{array}$ & $\begin{array}{l}\text { 1. } \begin{array}{l}\text { Baik = skor } 6- \\
10\end{array} \\
\text { 2. } \begin{array}{l}\text { Buruk = skor } \\
0-5\end{array}\end{array}$ & Ordinal \\
\hline
\end{tabular}

\section{HASIL DAN PEMBAHASAN}

Hubungan Tindakan Ibu Tentang Peningkatan Status Gizi Balita Yang Mengalami Gizi Kurang Di Puskesmas Bromo Medan Tahun 2018

Tabel 2

\begin{tabular}{cccccccc}
\hline \multirow{2}{*}{ Tindak } & \multicolumn{9}{c}{ Status Gizi Balita } & \multicolumn{2}{c}{$\boldsymbol{p}$-value } \\
\cline { 2 - 7 } an & \multicolumn{2}{c}{ Baik } & \multicolumn{2}{c}{ Buruk } & \multicolumn{2}{c}{ Total } & \\
\cline { 2 - 7 } & $\mathbf{F}$ & $\mathbf{\%}$ & $\mathbf{F}$ & $\mathbf{\%}$ & $\mathbf{F}$ & $\mathbf{\%}$ & \\
\hline Baik & 6 & 26,1 & 0 & 0 & 6 & 26,1 & 0,002 \\
Buruk & 4 & 17,4 & 13 & 56,5 & 17 & 73,9 & \\
\hline Total & $\mathbf{1 0}$ & $\mathbf{4 3 , 5}$ & $\mathbf{1 3}$ & $\mathbf{5 6 , 5}$ & $\mathbf{2 3}$ & $\mathbf{1 0 0}$ & \\
\hline
\end{tabular}


Hubungan pengetahuan ibu tentang peningkatan status gizi balita yang mengalami gizi kurang Di Puskesmas Bromo Medan tahun 2018 mayoritas pengetahuan cukup dengan status gizi balita buruk sebesar 7 responden $(30,4 \%)$ dan baik sebesar 5 responden $(21,7 \%)$.

Pendidikan

dapat

mempengaruhi proses belajar seseorang, semakin tinggi pendidikan seseorang akan mudah dalam menerima informasi yang ada. Semakin banyak informasi yang masuk maka semakin banyak pengetahuan yang didapat termasuk informasi mengenai kesehatan (Widayatun, 2004).

Penelitian ini sejalan dengan penelitian yang dilakukan oleh Wahyani di Yogyakarta bahwa ada hubungan tingkat pengetahuan ibu tentang gizi balita dengan status gizi balita di wilayah kerja Puskesmas Pleret Bantul Yogyakarta (Wahyani, 2013). Hasil penelitian ini juga didukung oleh penelitian yang dilakukan Putri dkk (2015), yang menunjukkan adanya hubungan yang signifikan antara tingkat pendidikan dan pengetahuan ibu dengan status gizi balita di Padang (Putri dkk, 2015).

\section{Pendidikan}

dapat

mempengaruhi proses belajar seseorang, semakin tinggi pendidikan seseorang akan mudah dalam menerima informasi yang ada. Semakin banyak informasi yang masuk maka semakin banyak pengetahuan yang didapat termasuk informasi mengenai kesehatan (Widayatun, 2004).

Pada penelitian ini, analisa yang digunakan adalah menggunakan chi square. Hasil analisa statistik diperoleh $\mathrm{p}$ value $0,027(p<0,05)$. Hasil penelitian ini menunjukkan $\mathrm{Ha}$ diterima Ho ditolak yang artinya ada hubungan pengetahuan ibu tentang peningkatan status gizi balita yang mengalami gizi kurang Di Puskesmas Bromo Medan tahun 2018.

Berdasarkan hasil statistic dengan menggunakan uji fisher exact test menunjukkan Ho ditolak $p$ value $0,027(p<0,05)$, artinya ada hubungan pengetahuan ibu tentang peningkatan status gizi balita yang mengalami gizi kurang Di Puskesmas Bromo Medan tahun 2018.

\section{KESIMPULAN}

Hasil penelitian menunjukkan $\mathrm{H}_{\mathrm{a}}$ diterima $\mathrm{H}_{\mathrm{o}}$ ditolak yang artinya ada hubungan pengetahuan dan tindakan ibutentang peningkatan status gizi balita yang mengalami gizi kurang di Puskesmas Bromo tahun 2018 


\section{DAFTAR PUSTAKA}

Aditianti.,Prihartini, S., Hermina., 2016. Pengetahuan, Sikap dan Perilaku Individu tentang Makanan Beraneka Ragam sebagai Salah Satu Indikator Keluarga Sadar Gizi (KADARZI).Buletin penelitian kesehatan, Vol.44, No. 2, Juni 2016: 117-126. Jakarta

Adriani, M., dan Bambang, W., 2014.Gizi dan Kesehatan Balita.Jakarta: Kencana Prenada Media Grup. 2013.Pengantar Gizi Masyarakat.Jakarta: Kencana Prenada Media Grup. ., 2012.Peranan Gizi dalam Siklus Kehidupan. Jakarta: Kencana Prenada Media Grup

Almatsier, S., Susirah, S., Moesijanti, S., 2011.,Gizi Seimbang dalam Daur Kehidupan. Jakarta: Gramedia Pustaka Utama. 2010.Prinsip Dasar Ilmu Gizi. Jakarta: Gramedia Pustaka Utama.

Arifin, Z., 2015. Gambaran Pola Makan Anak Usia 3-5 Tahun Dengan Gizi Kurang di Pondok Bersalin Tri Sakti Balong Tani Kecamatan Jabon Sidoarjo.Midwiferia, 1(1), Sidoarjo. Arisman, M.B., 2014. Gizi dalam Daur Kehidupan. Jakarta: EGC.

Damanik, H., 2015. Hubungan Pola Makan Dengan Status Gizi Pada Balita Usia

1-4 Tahun di Lingkungan II Kelurahan Namo gajah Medan Tahun 2013.

Jurnal Ilmiah Keperawatan; 1(1) Februari 2015.

Donsu, J. (2016). Metodologi Penelitian Keperawatan. Yogyakarta : Pustaka Baru

Dinkes Kota Medan, 2016, Profil Kesehatan Kota Medan 2016 , Medan : Dinas Kesehatan Kota Medan

Kemenkes.(2017). Profil Kesehatan Indonesia 2016. Jakarta: Kementrian Kesehatan Republik Indonesia
Tahun 2015-2018. Jakarta: Direktorat Jenderal Bina Gizi dan Kesehatan Ibu dan Anak. 2010.Penuntun Hidup Sehat. Jakarta: Pusat Kesehatan.

Khomsan A., 2010. Pangandan Gizi untuk Kesehatan. Jakarta: PT. Grafindo Persada.

Marimbi, H., 2010. Tumbuh Kembang, Status Gizi dan Imunisasi Dasar pada Balita.Yogyakarta: Nuha Medika.

Mitayani.,danWiwi, S., 2010. Ilmu Gizi. Jakarta: Trans Info Media.

Notoatmodjo, S. (2010).Metodologi penelitian Kesehatan. Jakarta: Pt. Rineka Cipta

(2011). Kesehatan Masyarakat: Ilmu dan Seni. Jakarta: Rineka Cipta (2012). Promosi Kesehatan dan Perilaku Kesehatan. Jakarta: Rineka Cipta

Nursalam. (2011). Konsep dan penerapan metodologi penelitian ilmu Keperawatan ,Jakarta : Salemba Medika

Rahmawati, A.K. 2016.Hubungan Antara Pengetahuan Ibu tentang Gizi Seimbang dan Asupan Zat Gizi Makro pada Anak Usia 2-5 Tahun di Posyandu Gonilan Kartasura. Naskah Publikasi. Fakultas Kedokteran. Universitas Muhammadiyah Surakarta.

Rakhmawati, N. Z. 2014, Hubungan Pengetahuan dan sikap ibu dengan perilaku pemberian makanan anak usia 12 - 24 bulan, Jurnal Gizi Universitas Diponegoro. Vol3 no. 43 - 50.

Supariasa ID, 2017 .Penilaian Status Gizi , Jakarta : EGC

Suparlan., 2010. Kemiskinan di Perkotaan. Jakarta: PT.Obor Indonesia.

WHO., $2015 . \quad$ Healthy Diet. http://www.who.int/mediacentr e. diakses pada tanggal 30 januari 2017. WHO.,2016. Levels and trends in Child Malnutrition.

http://www.who.int/nutrition. Diakses tanggal 30 Januari 2017. 
p-ISSN : 2721-5393, e-ISSN : 2721-5385

www.jurnalp3k.com/index.php/J-P3K/index

Wardah, S.H., Ekayanti, I., 2014. Mother's Nutritional Behavior, Parenting Eating Pattern, Snack Contribution and Pre-School Children's Nutritional Status.Jurnal Gizi Pangan, Vol.9(3):145-150. Bogor. 